Revista Brasileira de Farmacognosia Brazilian Journal of Pharmacognosy 21(5): 814-817, Sep./Oct. 2011

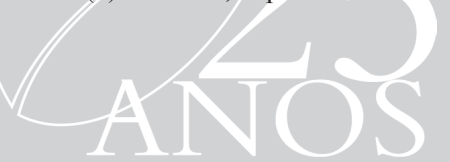

Article

Received 21 Dec 2010

Accepted 29 Mar 2011

Available online 12 Aug 2011

Keywords:

Dublin

ethnopharmacology

medicinal plants

natural products

ISSN 0102-695X

http://dx.doi.org/10.1590/S0102-

695X2011005000141

\section{Ethnopharmacology in Dublin: surveys on the medicinal plants use profile}

\author{
Francis Cunningham, Fabio S. Menezes*
}

\author{
School of Pharmacy and Pharmaceutical Scieces, Panoz Institute, Trinity College \\ Dublin, Ireland.
}

\begin{abstract}
This study aimed to examine the use of natural products as medicines in the greater Dublin area, Ireland. A field study was carried out on eighteen natural health stores; store assistants were interviewed and asked questions from a previously prepared questionnaire. Results were evaluated and a picture could be drawn about the use of natural products in Dublin. Questions asked included best sellers, new products on the market, common prescribers, ailments for which product is requested. Results indicated that as much as $60 \%$ of customers requests specific products were advice from staff. Nutritionists accounted for approximately one third of the medical profession that prescribed products for sale in health stores. The survey also examined common medicinal products requested which were not available without prescription. St. John's Wort and Gingko biloba were the most requested. Undoubtly, there is a revival to searching for natural alternatives for the treatment of diseases with no medical advice.
\end{abstract}

\section{Introduction}

Ethnopharmacology concerns the intersection of medical ethnography and biological studies of therapeutic action i.e., a transdisciplinary exploration that spans the biological and social sciences. (Etkin \& Elisabetsky, 2005). The main goal of ethnopharmacology has been to discover novel compounds, derived from plants and animals used in indigenous medical systems, which can be employed in the development of new pharmaceuticals (Waldstein, 2006). Ethnopharmacologic exploration, involving both field visits, as well as experimental research has lead in past to highly valuable information about medicinal plants used in different cultures and many were developed into drugs (Bruhn \& Holmstedt, 1981; Farnsworth et al., 1985). In years past enormous ethnopharmacological research was carried out by in the early days of medicinal plant research 250 years ago.

Ethnopharmacology was initiated by the missionaries in the colonies interested in the use of pharmacologically active plants, like the Jesuits in $16^{\text {th }}$ century Latin America (Anagnostou, 2005). Throughout that time, anthropologists worked together with chemists and biochemists often leading to fruitful collaborations. Examples of such partnerships are the isolation of caffeine by Johann Wolfgang von Goethe and Friedlieb Ferdinand Runge, and the elucidation of the pharmacological principles in foxglove (Digitalis spp.). Typically, ethnopharmacological discoveries started with field observations and ended in new pharmacological insights. With the advancement of synthetic approaches in recent years, there has been a general lack of classical ethnopharmacological approaches in medicinal plant research both as a source of lead compounds for new drugs as well as in published research (Etkin, 2001; Cordell \& Colvard, 2005).

Another problem facing the future of ethnopharmacology is the highly competitive nature of drug research in the medical field. Thus, the success of drug discovery depends on the stringent criteria that help to avoid development of false positive candidates (Gertsch, 2009). As stated by Moerman (2008) "the low-hanging fruits have already been picked", the miracle molecule that can cure cancer and so forth will not be found easily.

Thus the aims of this study were to find out if naturally derived medicinal products are still used in Dublin city and if so, what uses they were intended for. Evaluating the main requests and uses of natural products is vital to filling a niche that is not fully filled by modern and more synthetically produced medicines. There are no records of any such interviews in the areas investigated, and thus the interviews carried out in health shops in the Dublin area were the first of their kind. 


\section{Materials and Methods}

\section{Fieldwork}

A total of eighteen health shops in the Dublin area were interviewed to gather information on the different types of natural medicinal products supplied. A total of 34 trained staff members were interviewed with the prepared survey. The survey contained twelve questions, and asked in general to at least one person that worked in each health shop. To increase the number of answers, and therefore the accuracy of results two members of staff from each store were generally interviewed to remove any possible bias.

\section{Research site}

Dublin is the largest city and capital of Ireland (Figure 1). It is located near the midpoint of Ireland's east coast, at the mouth of the River Liffey. There are over 1,6 million residents in the county of Dublin. The use of Health shops in the Dublin area has increased in recent years as residents are becoming tired with the, perceived lack healthcare provided by the state. Statistics provided in 2007 by the central statistics office showed the following about Ireland health system; $47.6 \%$ of Ireland's population were covered by private health insurance, and $31.9 \%$ of the population were covered by Medical Cards, and there were 53 publicly-funded acute hospitals, with a total of 12,094 in-patient beds available and 1,253 day beds available.

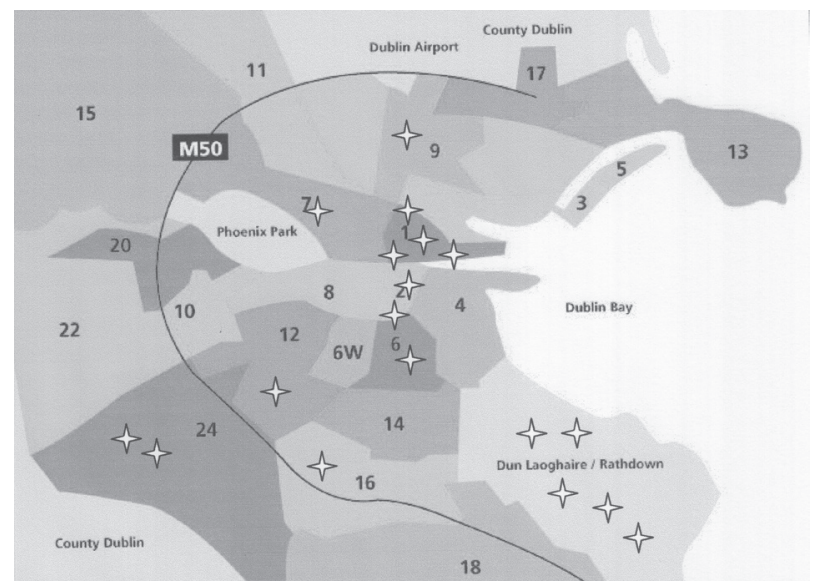

Figure 1. Map of Dublin City and its neighbourhoods (numbers are the postcode areas in the inner city) and the areas where shops were visited to gather information on medicinal plants/natural products use (stars).

The map provided in Figure 1 shows the greater Dublin area divided into sections based on postcode. A sample of stores from a broad area in Dublin was undertaken. Areas in the South and South east of the county are generally considered more affluent from the map that can be seen as areas 6, 14 and the constituencies of Rathdown/Dun Laoghaire. Areas such as Dublin 24, 1, and 7 would be viewed upon as having lower income families. Whilst carrying out the survey these observations were validated by staff members. General cold and flu preparations were very common requests in the poorer areas, whilst a wider choice of medicines was requested in the more affluent areas. Examples included anti-ageing products, vitamin supplements, and a wide range of health food organically grown and harvested.

Many of the shops, although natural health stores, had very different functions to the community. While some focused purely on the medicinal side others focused more on a dietary approach thus giving a wider range of answers to the questions asked. To tailor for this the questions were adapted, if required, to allow the maximum amount of information to be gathered. During the month of October, the selected health stores were visited on the list provided.

The following stores were selected: 1 . Country Cellar, 8 Patrick St. Dun Laoghaire; 2. General Health Food Store, GPO Arcade Dublin 1; 3. Health Matters, Ashleaf S.C. Crumlin Dublin 12; 4. Health Matters, 8 Grafton St. Dublin 2; 5. Hopsack Health Store, The Swan Centre Rathmines; 6. La Sante, Marine Mall Dun Laoghaire; 7. Nourish, GPO Arcade Dublin 1; 8. Nourish, Liffey St. Dublin 1; 9. Nourish, 16 Wicklow St. Dublin 1; 10. Organic Supermarket, 2c Main Street, Blackrock; 11. The Health Store, The Square Tallaght Dublin 24; 12. The Health Store, Nutgrove Office Park Dublin 24.; 13. Vegeplanet, 19a Main Street Blackrock Market; 14. Down To Earth, Great Georges Street South Dublin; 15. Full life health food store, Dun Laoghaire shopping centre; 16. Nature Store, 324A NCR Phibsboro Dublin 7; 17. Nourish, Omni S.C Santry Dublin 9; 18. Nourish, Nutgrove S.C. Rathfarnham Dublin 16.

\section{Questionnaire}

1. What is the main natural product sold in your shop? 2. What is the main complaint presented by customers that require the use of Natural Medicines from your shop?

3. What are the most commonly sold new releases at the moment?

4. What are the main side effects that you know about if any associated with Natural products that were investigated?

5. Is there any particular plant that you don't sell for which people request?

6. If yes what is the plant used for?

7. How many people come in on a daily basis to buy natural products without any previous advice? 
8. How many people come in on a daily basis to buy natural products knowing exactly what they want or a detailed knowledge on the subject?

9. What are the main "prescribers" for Natural products? Acupuncturists, healers or reiki, shiatsu, homeopathy, chiropractic, osteopathy, reflexology, naturopathy or anthroposophy. Kinesiologists were later added to the list due to the volume of answers it was included in.

10. Do you have any product which the main claim is to protect against oxidative disorders or oxidative stress or excess free radicals or could have anti ageing properties?

11. Do you only sell manufactured products or do you sell any medicinal plants just dried or fresh with no manufacturing?

12. If so what is the best seller?

\section{Results and Discussion}

The main results show Echinacea as the main "natural remedy" sold in Dublin. Other herbal remedies that were in the top ten sellers included green/white tea, flaxseed and elderberry (Figure 2).

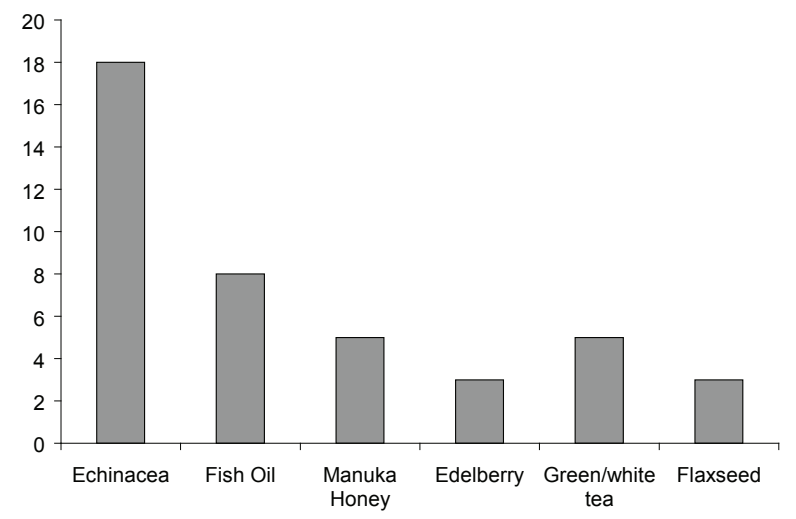

Figure 2. Main products sold in health shops in Dublin $(\mathrm{Y}=$ number of staff answers).

Regarding the plants not available, Ginkgo biloba, St. John's Wort (Hypericum perforatum), Cannabis (for arthritis) and Tribulus were the most requested (Figure 3). Ginkgo biloba is a medicinal plant used for the treatment of several conditions related to oxidative stress that is just available in Ireland under prescription. The same applies to St. John's Wort, Hypericum perforatum, a plant used for the treatment of depression. Cannabis sativa, a drug of abuse, is constantly asked in shops for the treatment of arthritic pains. Tribulus terrestris, a plant used as aphrodisiac due to the contents of saponins is stated to possess androgenic activities and this is probably the reason why it is looked for. Around $60 \%$ of the population that enter health shops to buy these natural products have at least moderate knowledge on the relevant plant and how to use such medicinal product. The main prescribers of natural products, including plants, are nutritionists and kinesiologists, followed by a third category that encompasses all the other complementary and alternative medicine prescribers (Figure 4).

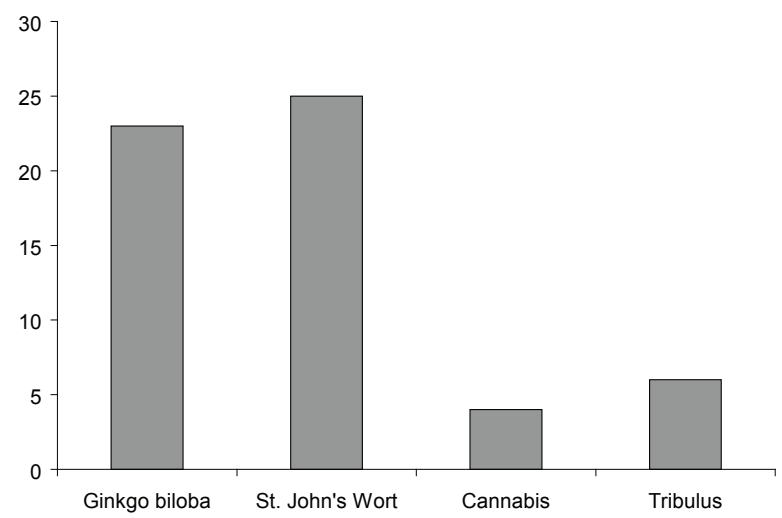

Figure 3. Plants not available in health shops that are constantly asked about $(\mathrm{Y}=$ number of staff answers $)$.

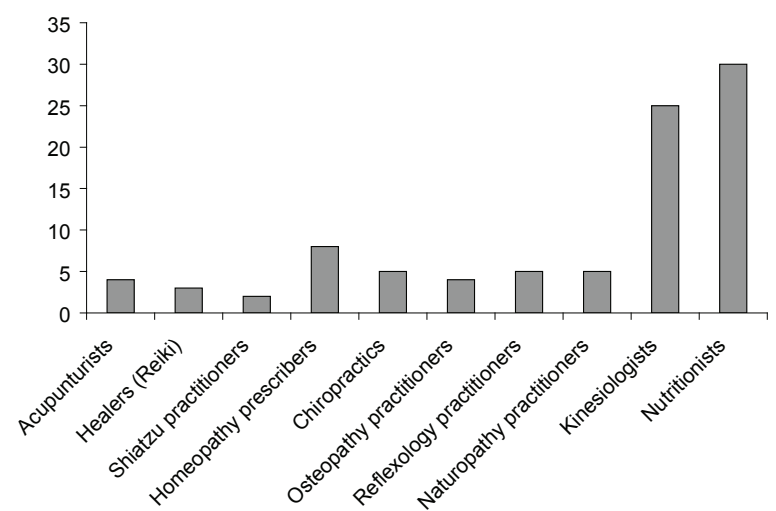

Figure 4. Main prescribers of Natural Products and medicinal plants ( $\mathrm{Y}=$ number of staff answers).

Natural products or medicinal plants available in Ireland must first pass stringent safety tests before they are available to the public in an OTC manner (Over the counter, i.e. no formal prescription needed) manner. There is no recognition of phytotherapy or medicinal plants use by any Irish Medical Board. What is interesting though is that the use of plant derived remedies is still a vital area in medicinal product invention. Approximately $60 \%$ of the anti-tumoral and anti-infective agents, either commercially available or in late stages of clinical trials are of natural origin (Silva et al., 2005). However at present there is no single prescribed medication existing (with an active principle isolated or inspired by plant metabolism) on the world market that is off plant origin and as a result this puts a great emphasis on health stores to fill this niche.

It is also interesting to see the main reasons why people enter in a health shop to buy medicines. There are usually a broad variety of ailments they are seeking treatment for; however it is always mentioned, among the diseases themselves, the fact that people are seeking other 
approaches for one main reason, dissatisfaction with other medicinal approaches and current medicine (Figure 5).

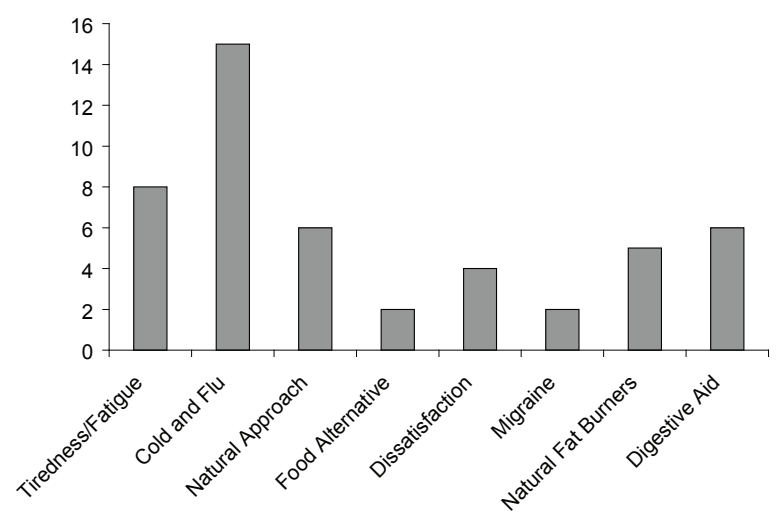

Figure 5. Main reasons of Natural Products/Medicinal Plants use in Dublin ( $\mathrm{Y}=$ number of staff answers).

Echinacea and general multi-vitamin were the dominant products selling in the health stores visited. When the survey was carried out, in early October, the swine flu epidemic had just become publicized; along with the impending winter sales of medicines with the ability to boost immune function, were among the best sellers, hence its position as the number one seller. The second best seller, multi-vitamins (not shown in Figure 2), was number 1 for the rest of the year commonly, as stated by staff when the interview was conducted. Staff claimed this reason was due to customer request for a supplement that could re-energize and reduce fatigue. From the survey it becomes apparent that there is an almost equal amount of people that enter stores with a clear view on what they want, to those who enter and seek advice.

There were also two clear products for which patients had researched privately and requested in these stores, which could not be legally sold. The two products were Gingko biloba and St. John's Wort, the former available in the United Kingdom and the later being made prescription only in 2000 . Nutritionists were named by all health stores as the main prescribers of their medicines. Kinesiologists, which had been previously been excluded from the list was the second highest profession prescribing natural medicinal products. All others professions appeared with approximately the same ratio of prescriptions. All stores stated that prescribing was generally from a mixture of all the professions present on the list. The main reason for potential patients visiting health stores at the time of visiting was for herbal products for the prophylaxis of cold and flu's. Mentioned previously personnel in the stores visited stressed the point that many people had become worried about contracting such diseases and the public outbreak of the H1N1 virus had caused people to become more fearful of their health. The general pattern of the oncoming winter season and outbreak of new diseases annually ensures that preparations with immune boosting function become the largest seller at that period.

The second largest reason for the rise in popularity of Health Stores was a more natural approach to health. Many of the store assistants interviewed said that people purchasing medicines from their store were becoming weary of general practitioners and pharmacies and believed natural remedies would provide a safer option.

\section{Acknowledgment}

The authors would like to thank the staff from the Pharmacognosy area in the School of Pharmacy and Pharmaceutical Sciences, Trinity College Dublin, especially Mr. Joe O'Reilly.

\section{References}

Anagnostou S 2005. Jesuits in Spanish America: contributions to the exploration of the American materia medica. Pharmacy in Histor, 47: 3-17.

Bruhn JG, Holmstedt B 1981. Ethnopharmacology: objectives, principles and perspectives. In: Beal JL, Reinhard E (Eds.), Natural Products as Medicinal Agents. Hippocrates-Verlag, Stuttgart, p. 405-430.

Cordell GA, Colvard MD 2005 Some thoughts on the future of ethnopharmacology. J Ethnopharmacol 100: 5-14.

Etkin NL 2001. Perspectives in ethnopharmacology: forging a closer link between bioscience and traditional empirical knowledge. J Ethnopharmacol 76: 177-182.

Etkin NL, Elisabetsky E 2005. Seeking a transdisciplinary and culturally germane science: the future of ethnopharmacology. J Ethnopharmacol 100: 23-26.

Farnsworth NR, Akerele O, Bingel AS, Soejarto DD, Guo Z 1985. Medicinal plants in therapy. B World Health Organ 63: $965-981$.

Gertsch J 2009. How scientific is the science in ethnopharmacology? Historical perspectives and epistemological problems. J Ethnopharmacol 122: 177183.

Moerman DE 2008. Personal Communication at the $10^{\text {th }}$ International Congress of Ethnopharmacoloy 16-19 September, Sao Paulo, Brazil.

Silva CG, Herdero RS, Mathias CJ, Panek AD, Silveira CS, Rodrigues VP, Renno MN, Falcao DQ, Cerqueira DM, Minto ABM, Nogueira FLP, Quaresma CH, Silva JFM, Menezes FS, Eleutherio ECA 2005. Evaluation of antioxidant activity of Brazilian plants. Pharmacol Res 52: 229-233.

Waldstein A 2006. Mexican migrant ethnopharmacology: Pharmacopoeia, classification of medicines and explanations of efficacy. J Ethnopharmacol 108: 299-310.

\section{*Correspondence}

Fabio S. Menezes

School of Pharmacy and Pharmaceutical Scieces, Panoz Institute, Trinity College Dublin, Ireland

desouzaf@tcd.ie

Tel. +35318964154

Fax: +35318962810 